\title{
4
}

\section{Obesity, Biopower, and Embodiment of Caring: Foodwork and Maternal Ambivalences in Ho Chi Minh City}

\author{
Judith Ehlert
}

\section{Introduction}

An article titled "Alert: children with fat bellies" in a local newspaper ${ }^{1}$ published in 2015 drew public attention to the growing phenomenon of obesity in children in Ho Chi Minh City (HCMC). Besides the lack of physical activity, the article points to the increase of high-calorific food consumption as one reason for this development. The economic reforms of Đổi Mói i 1986 went hand in hand with the modernisation of the food system, with dietary patterns gradually changing towards the consumption of more processed, convenience, and high-calorie foods (see Ehlert and Faltmann, this volume). With growing economic affluence and dietary patterns changing, Vietnam is said to be undergoing a phase of nutrition transition. For the first time in the country's history being overweight and obesity especially in children proliferate as public health concerns and make the Vietnamese government respond by a comprehensive mission for their eradication by 2030. Health and nutrition

J. Ehlert $(\bowtie)$

Department of Development Studies, University of Vienna, Vienna, Austria e-mail: judith.ehlert@univie.ac.at 
education programmes first and foremost target parents of children under the age of five years and the children themselves living in urban areas-a cohort that was found most at risk (Vietnam Ministry of Health 2012).

The World Health Organization (WHO) defines obesity as "abnormal or excessive fat accumulation that may impair health" (WHO 2018). While it used to be considered a problem of the Global North, obesity is perceived as the nearest future concern of low- and middle-income countries, with Asia already being highly affected (WHO 2018). Scholars from the broad field of critical health, obesity, and fat studies criticise the medicalised discourse of 'obesity' on the basis of it constructing fatness as a unidirectional health problem. This critical scholarship argues that the dominant discourse constructs obesity as one of the major food anxieties of our time that supposedly puts public health systems as well as the productive labour force of whole economies under pressure (WHO 2000; Guthmann 2009; Metzl and Kirkland 2010; LeBesco 2011; Lupton 2013). For the context of China, critical voices on obesity argue that the 'obesity epidemic' deemed culturally favoured body fatness in children pathological (Greenhalgh 2016). ${ }^{2}$ Similarly in Vietnam, the chubby shape of a child's body becomes vested with conflicting meanings, ranging from the beauty of chubby children to "children with fat bellies" perceived as "alarming", as exemplified in the headline of the local newspaper above. Whereas the medical and nutrition sciences dominate research on child obesity in Vietnam, a critical social science perspective on the topic hardly exists.

Therefore, the emerging obesity discourse in Vietnam constitutes the scaffold for the following empirical study. Coming from the background of sociology and critical development studies, the author's interest lies in deconstructing the discourse by engaging with the everyday routines, social relations, and practices of mothers' foodwork ${ }^{3}$ in urban Vietnam. The chapter develops the argument that food anxiety derives from the ambivalences that women experience in their daily practices as 'caring' mothers. Socio-cultural norms articulated in public health discourses, taken up by the food industry, discussed in social media platforms, as well as emphasised by family, friends, and neighbours all address very different expectations regarding a child's body shape and health status. These conflicting discourses are not only inscribed on the child's body but work on and in the mother's body as well. 
This chapter is in keeping with Cairns and Johnston $(2015,25)$ in their sociological approach to food femininities, which establishes the link between individual food and body performances at interpersonal and emotional levels and the social structures and institutions these are embedded in. In general, the regulation of food, food-related entitlements, and responsibilities are structured along gendered lines, strongly associating foodwork with feminine identity (Charles and Kerr 1988; DeVault 1991; Counihan 1999). To this end, however, it is by no means to say here that women ${ }^{4}$ are considered as 'naturally' caring, nor that something like a general motherhood experience exists. By contrast, the chapter aims to better contextualise how women in HCMC manoeuvre dominant socio-cultural discourses that essentialise maternal love by connecting it with food and body work (Collins 1994). The following study thus brings in the perspectives of married women in their 20 s to 40 s, all holding a university degree, working in full-time employment, and having one to three children. Given their social 'middle-class' ${ }^{5}$ position, they command the (economic) means to participate in the emerging lifestyle, food, and body industries in the city. The concise focus of the study implies its very limitation at the same time, namely the exclusion of perspectives of women who are structurally deprived of access to certain spaces of urban consumption.

This chapter draws on data from different periods of field research in HCMC between 2014 and 2017. The main data for this study was gathered in the summer months of 2015 . Back then, the author was pregnant herself - a circumstance that surely helped open up access to other women and ample opportunities for informal discussions on the research topic. Through the regular attendance in a prenatal class the author met women sharing ideas of what they considered good for their (unborn) babies and on how they regulated their food consumption during pregnancy. The contact to this prenatal class in the hospital was provided by Loan, ${ }^{6}$ the owner of a women's spa in HCMC specialising in services for mothers and mothers-to-be. Furthermore, interviews ${ }^{7}$ were conducted with Ly, a female editor of a popular women's and family lifestyle magazine to get a first-hand idea on 'modern' mothering and feeding trends. Thi, interviewed in her capacity as staff of a local market research institute, shared insights not only into urban consumption trends but also on 
her personal experience of mothering. This chapter also refers to the narratives of Veronique - a French woman with two kids and married to a Vietnamese-a representative of a supermarket chain. Back then, she had just had her first baby and the discussion naturally diverted to her personal observations of women 'stuffing' their children. This was the first time that the topic of child 'obesity' and the ideal of plump body figures in children popped up as a dimension of this research. An interview with a representative of the Nutrition Centre in Hanoi, ${ }^{8}$ with a medical doctor as well as a personal fitness coach complements the subjective experiences of the mothers interviewed by bringing in perspectives of the public health sector and fitness industry. Participant observation in condominium blocks, restaurants, shopping malls, and supermarkets enriched the data collected. Moreover, this chapter builds on internet research that explored the role of social media platforms and online forums on child nutrition. Local online newspapers were scanned by search engine tools to investigate the use of terms like 'feeding practices' (cách thúc cho trẻ/bé $a \breve{n}$ ) and 'a good mother' (một người mẹ tôt) in media discussions.

\section{Biopower, Obesity, and Maternal Caring}

This section briefly introduces the background of nutrition transition and related weight gain of children in urban Vietnam. Its main goal is to provide a conceptual framing for the understanding of the local phenomenon of obesity - as discourse. The public health sector and the role of the food industry are addressed in terms of their biopower over children's health. Furthermore, the public debate on childhood obesity is put in perspective through pinpointing the dominant narrative of 'proper mothering' assigning women with a 'natural' responsibility for feeding their children in contemporary Vietnam.

\section{Biopower Over Eating Bodies}

Biopower in the Foucauldian sense refers to the regulation of bodies through appeals to life, risk, and responsibility (Monaghan et al. 2010). 
Whereas historically this power was executed by the sovereign invested with the right to decide over death and life of his subjects, biopower turns into a more abstract mechanism to rationally organise and control the vital character of contemporary societies (Foucault 1977). No longer is power understood as the asset of a sovereign entity but as relationally bound in and oscillating between different bio-authorities. Their authority is embedded in (several) truth discourses towards human existence and in their acknowledged capacity of problematising and strategising rational interventions in the collective body of the population in the name of controlling and fostering its life and health (Rabinow and Rose 2006). Moreover, modes of subjectification are central elements of biopower "through which individuals are brought to work on themselves, under certain forms of authority, in relation to truth discourses, by means of practices of the self, in the name of their own life or health, that of their family or some other collectivity, or indeed in the name of the life or health of the population as a whole" (Rabinow and Rose 2006, 197).

In Foucauldian-coined governmentality studies, biopower is oftentimes drawn on to explain the effect of neoliberal political-economic contexts (Harvey 2005) on self-governing subjects in relation to food. In a self-disciplining mode, individuals unconsciously embody discourses stressing consumer choice and individual responsibility for well-being, health, and happiness when engaging with the food system as 'free consumer subjects' (Parsons 2015, 7; Cairns and Johnston 2015, 33). This theoretical lens is prominently drawn on by scholars to understand, for example, organic food consumers pursuing safe and healthy food options as a way to navigate food system risks (Cairns et al. 2013; see Faltmann, this volume) and in their creation of healthy bodies through self-care regimes and health optimisation (Lupton 1997; Shilling 2002). Besides, critical obesity studies are strongly framed within the same parlance of neoliberal governmentality. In Foucauldian critique, scholars, for example, focus on the social (de)construction of the self-indulging body as abject and morally transgressive-the incapacity of a person's selfdiscipline, the lack of individual responsibility towards his or herself and society as a whole reflected in the fat body (e.g. Wright and Harwood 2009; Metzl and Kirkland 2010; LeBesco 2011; Abbots 2017, 139). Critical obesity scholars focus on the categorisation of pathologic bodies 
and 'normal' bodies along the truth regimes provided for by, for example, the medical and nutrition sciences and their matrixes, statistics, and indices such as the Body Mass Index (BMI) (Monaghan et al. 2010, 47ff.).

Given the way obesity is critically addressed in studies-mainly pertaining to contexts in the Global North-this chapter provides in the following for the contextualisation of such an approach in the Global South. It does so by stressing the complexity, ambiguities, and differing rationales of bio-authorities which work on the child's body in Vietnam. There, the discursive construction of normal and abject children's bodies is way less clear-cut than the dichotomy of the fat/'abject' body and the healthy/'normal' body for neoliberal contexts would commonly suggest. In a first step, however, the context of the study needs to be established by outlining the obesity discourse and its prominent authorities of truth in Vietnam.

\section{Obesity, Public Health, and the Economy of Caring in Vietnam}

After decades of food insecurity affected by the country's war-torn history, Vietnam's economic upswing came along rapid processes of industrialisation and urbanisation that also provided for a restructuring of the food sector as a whole (see Ehlert and Faltmann, this volume; see Figuié et al., this volume). The food distribution and retail sector today constitutes one of the hottest markets attracting domestic and foreign direct investments (Mergenthaler 2008, 6f.; Hai Thi Hong Nguyen et al. 2013). Supermarkets in major cities such as HCMC offer convenience and globally branded products (Cadhilon et al. 2006). They are usually integrated with huge shopping malls and, especially at nights and weekends, frequented for leisure and recreational purposes (Ehlert 2016). Next to the retail sector, the gastronomic sector constitutes a vibrant and expanding market, with Western-style fast food especially constantly gaining in popularity (Q \& Me Vietnam Market Research 2016). In summary, 'Big Food'—a popular term subsuming the corporate power of global food companies dominating food chains from production to retail on a worldwide scale (Nestlé 2013; Clapp and Scrinis 2017) — has long seized the economic potential of the Vietnamese market (see Ehlert and Faltmann, this volume). 
Đổi Mớis 'open door' policies of the mid-1980s (Beresford 2001, 2008) have stimulated the development of new food consumption patterns, most strikingly in urban areas. Vietnam is said to have entered a phase of "nutrition transition" (Sobal 1999, 178) as a consequence of the changing local food and nutrition system (Nguyen Cong Khan and $\mathrm{Ha}$ Huy Khoi 2008; Walls et al. 2009). Dietary patterns are changing due to increased consumption of processed and convenience foods, meat, as well as of high-calorie foods (Vietnam Ministry of Health 2012).

Unknown before 1995, overweight and obesity have turned into major public health issues in Vietnam recently. According to findings of the nutrition sciences, overweight and obesity is growing rapidly among children under the age of five living in urban centres (Vietnam Ministry of Health 2012). In response to such emerging food-related health concerns, the government launched a National Nutrition Strategy for 2011-2020, including a vision for its eradication by 2030 (Socialist Republic of Vietnam 2012). Through nutrition and health education and public awareness campaigns, the government aims to correct such pitfalls of rapid market integration. Organisations such as Vietnam's Nutrition Association (VNA) or the National Institute of Nutrition (NIN) periodically survey the food-related health problems of the population. The medical system is vested with the authority to confront the country's nutrition transition problems. Regular health, weight, and BMI statistics professionalise the obesity discourse (Vietnam Ministry of Health 2016), which is widely taken up by local press. However, as we will see, this medical discourse of an alarming rise in child obesity is not fully embedded in the everyday realities of feeding children, but rather is just one of the competing truth discourses on the body ideal for children.

In this context of emerging consumerism, food advertisements are omnipresent in providing lifestyle imaginaries of 'free' consumer choice in HCMC (see Ehlert and Faltmann, this volume). Advertisements framing the city roads, TV ads, and popular magazines, the food and lifestyle industries constantly call for the consumption of convenient foods, fast food, and dairy products, enjoying beverages and confectionary (on China, see Jing 2000) (Fieldnotes, 09/2014). On fast food consumption, Thi explained: 
So because we have money and then we just want to make our baby, our kid happy. And then, you know it is also a good place for a family catch up, for a family hang out. So I can go there with my friend's family. So kids can play together and everyone is happy. So that is why we still go there. Even when we know it is not good. And then you know [in Vietnam], we have more money so we can afford more things to the kid and just want to make the kid happy. (Interview, 09/2015)

The quote by Thi points to the conflict that resonates in the felt need to make "the kids happy" and, at the same time, being aware that the food offered in respective places "is not good". In her critical approach to the 'obesity epidemic' in China, Greenhalgh $(2016,487)$ takes up this ambivalence tainted with conflictive emotions as being a structural characteristic of 'Big Food', 'Big Soda', and 'Big Pharma'. According to her, huge profits in newly emerging lifestyle industries - ranging from the food and beverage industries over the gastronomic sector to diet and fitness markets-back up the 'obesity epidemic'. The same globally operating economic system that calls for relentless consumption offers the products to fight the externalities that it creates in the first place. The food and diet industries, that structurally condition and boost each other, co-opt emotions when working with 'maternal affection' and 'love' to symbolically enrich the products they sale. This can be referred to as the 'economy of caring'. The industrialised, large-scale conventional food system subjects eating bodies by craving them into certain food tastes and emotions (Carolan 2011). 'Big Food' symbolically sells the truth of happiness and well-being. For consumers, who failed in their "agency" to choose "wisely" (Parsons 2015, 7), 'Big Food' puts them back on the 'right', self-responsible track. Depending on the specific beauty and body ideals in a given local market, 'Big Food' is able to provide tailor-made products producing certain kinds of bodies_-for example, dieting products to lose weight or high-calorie food to explicitly gain weight.

\section{The Dominant Mothering Discourse}

With children overeating supposedly turning into a public health problem, the government calls on the family's responsibility to educate and 
socialise children in a way that aligns with the ideal of a healthy and harmonious Vietnamese society. State equality discourses following Đổi Mó $i$ picked up the family as "a bulkwark against the disintegrative effects of market change" and shifted attention of gender equality in terms of social equity to gender relations within the family (Werner 2009, 75). Families were promoted as anchors for managing the post- Đổi Mới vagaries of social disintegration. Women were acknowledged as "most efficient link in family culture: they are the soul of the family and the warm sentimental fire of the family" - herewith addressing women's responsibility for childcare and caring for the elderly (Werner 2009, 75, referring to Resolution 42. 04/TW of the Communist Party of Vietnam).

In a survey conducted by the VNA in 2013 on feeding children, generally 'the parents' were addressed in their role of food socialisation. The interview with the Secretary General of the VNA presenting the survey, however, shows the continuance of discursively domesticising women and foodwork, the latter perceived as a symbol for the affection between mother and child:

Nowadays, many mothers are only present at the family's dinner. This has led to difficulties in the children's eating. Children want to eat the food cooked/prepared by their mothers, because no one else can understand them as well/ be as close to them as their mothers. (Tuổi Trẻ Online 2013) ${ }^{9}$

The quote by the nutritionist represents the approach of the public health sector prioritising family meals as important factor for properly socialising children into food experiences. This perspective holds that children desire to have their mothers involved in their food encounters at home. Being present at and preparing for family meals becomes set as a bar of 'good motherhood'. A woman's foodwork thus persists being considered one of the paramount performances of her femininity.

Contemporary discourses on femininity in Vietnam are rooted in Confucianist norms ${ }^{10}$ of the woman of virtue ${ }^{11}$ (Ngo Thi Ngan Binh 2004) intertwined with socialist ideals of gender equality (Rydstrøm 2011). Both engrain the female and the male body in the cosmological and social order. The relativist system of Yin and Yang in Confucianism draws on female and male bodily dispositions and forces through which 
the 'natural' characters of women and men can be inferred. Similarly, state-driven gender discourses channelled through the state-organised Women's Union (Waibel and Glück 2013) deduce female traits, capabilities, and social functions strongly from women's biological sex and physiological disposition. The reproductive function of the female body in terms of, for example, her childbearing and breastfeeding capacity assigns the woman with a "natural vocation" (thiên chüc) (Rydstrøm $2004,2011,174 f$.). From the basis of her corporality she is expected to develop into a woman of virtue as would show in herself-controlled and self-sacrificing responsibility for the nurturing of the family (Ngo Thi Ngan Binh 2004). Bélanger (2004), in her study on childless and single women in Vietnam, brings to the fore the social construction of motherhood and caring conceived of as the intrinsic parts of a woman's identity in patrilineal context extending beyond the family. Moreover, women's reproductive and caring roles are emphasised as crucial for the reconstitution and revitalisation of the nation (Drummond and Rydstrøm 2004, 3 ). The subjectification of the dominant motherhood discourse makes women work on themselves in the name of their children and that of the Vietnamese nation (Drummond and Rydstrøm 2004, 3; Rabinow and Rose 2006, 197).

This section provided an overview against which the further narratives of the female interviewees should be read. It has been shown that the 'problem' of obesity strongly aligns with a dominant mothering discourse, which first and foremost holds women responsible for socialising their children into healthy eaters. At the same time, the bio-authority of the economy of caring — stylised here as 'Big Food'-co-opts both the discourses on obesity and proper motherhood, as we will see in the following.

\section{Biopower and the Embodiment of Caring}

As suggested by Shilling $(2012,44)$, "[t]he spotlight shines on certain aspects of the body leaving others obscured". He refers to a division between those scholars who focus on the body as object that is rendered passive from without by changing regulating authorities and modes of biopower in the Foucauldian sense, and on the other side those engaging 
with the body as a 'lived' space of subjective, sensual experiences of "beingin-the-world" as conceptualised in the phenomenology of the body (Csordas 1994, 10). In reference to food consumption, the latter means that "eating [and being fed] is an experience through which people materially and viscerally taste, smell, feel and sense food" (Abbots 2017, 19f.).

Thus far, obesity has been introduced as a discourse, marking the 'obese' against the 'normal' body and the respective role assigned to women in producing such kinds of children's bodies. The following will integrate these notions of the 'outer' and the 'inner' body-or 'body as object' and the 'lived body ${ }^{12}$ _ by discussing how subjective embodied experience and socio-cultural frames are entangled in the mundane practice of eating and feeding others.

This section highlights both the child's and the mother's bodies as objects addressed by different bio-authorities; and approaches the lived experiences of these bodies. In keeping with Abbots $(2017,142)$ what is perceived as normal/abnormal children's bodies and what as 'good mothering' is more than just a social construction but always and deeply related to the materiality of bodies and the way one feels from within. The latter will be discussed in terms of emotions such as failure and shame of not having reached the mothering ideal, shyness because of one's own body, as well as along bodily sensations such as taste, satiety, and hunger (Crossley 2012, 139f.). It will be argued that a more contextualised understanding of socially structured food anxieties in contemporary urban Vietnam is only possible through reference to both biopower and the embodiment of caring.

\section{Embodiment of Motherhood (Discourses): The Milk of Love}

As will be shown in the following ideals of motherhood, public health recommendations and 'Big Food's' economy of caring already intimately work on the pregnant body of mothers-to-be, who start regulating their own bodies and appetites when carrying their unborn children.

In a social media forum, ${ }^{13}$ a young mother gave vent to her discomfort about the way society and the food industry in Vietnam intrude on 
mothers by instructing them on how to bring up their children in ways to make them gain weight fast. Being overconcerned with baby's weight gain (see detailed below), mothers-to-be already start to compare their foetuses' weights in ultrasound scans. Since a woman's capacity to breastfeed her newborn properly is rendered an essential feature of her femininity (see above), women easily "get scolded" for having breastmilk that is too "weak and fluid" after birth. As consequence of the mother's bodily incapacity, the baby would fail to accumulate fat. In sympathetic response to this social media user's thread, many other young women recalled similar intimidating experiences of being blamed and feeling ashamed for having 'weak' breastmilk and thus being considered unable to properly nurture their newborns. Young mothers would be accused of "not having eaten well enough" or of having "been too lazy to eat properly" during pregnancy-hence the failure of the baby to put on fat. This is why women, already during pregnancy, would try hard to ensure that "all nutrition will be absorbed by the foetus and not by the mother's body". The social media user criticised food companies for co-opting the social pressure faced by young mothers and for turning their distress into profit by "launch[ing] various types of pregnancy milk and vitamins ... in order to facilitate 'fat children and beautiful mothers' or 'smart children and slim mothers" (Vietnam's Nutrition Association 2017 $\mathrm{a}^{14}$ ).

Similar to the huge variety of infant formula, supermarkets promote a nearly unmanageable range of liquid milk products-from foreign imports to domestic brands, over flavoured snack-like drinks to ultraheat treated and sugar-added fresh milk. What is interesting is the availability of diverse brands and prices of pregnancy formula (Fieldnotes, 08/2015). Besides this, the dairy industry finds its way into the public health system via product placements. Very often commercial pregnancy formula and breastmilk substitutes are marketed in promotion areas near hospitals where women used to come for regular pregnancy check-ups (Interview, editor, 09/2015; Fieldnotes prenatal class, 10/2015).

The consumption of dairy in Vietnam in general has a long history in regards with social status aspiration. Milk was unavailable and foreign to local diets before French colonisation. In the late nineteenth century, cows bred for providing milk were for the first time imported from southern India when Tamil-owned dairies opened in Saigon. Back then, the 
French as well as the colonial Vietnamese middle-class preferred pasteurised, condensed, and fresh milk imports from France to the natural fresh milk available locally. Concerns for hygiene but especially claims of racial and social superiority led Vietnamese consumers to buy imported milk (Peters 2012a, 190-197). Under French colonialism, advertisements for a French brand of condensed milk promised the plump child's future fortune and the parents' urban sophistication. The advertisement clearly pronounces strong class differences as written upon the portrayed child's body: in times scourged by the hardship of food scarcity for 'ordinary' people, the plump child symbolised the distinct power of an urban bureaucratic elite setting itself apart from 'backward' agrarian life and labour (Peters 2012b, 46ff.). Social status and economic means determined access to food and showed in well-fed bodies as compared to poverty and social marginalisation inscribed on meagre bodies. Seen in historical perspective, since its emergence in colonial urban Vietnam, milk used to symbolise upward mobility, the ability to personal advancement, and the connection with European etiquette.

Respective manufacturers seize on this strong historical association of milk consumption and social status aspiration as a crucial element in their marketing strategies. Whereas nearly every household uses baby formula, pregnancy milk formula is consumed by about $60 \%-70 \%$ of all households in the panel study for HCMC conducted by the local market research institute (Interview, representative research market institute, 09/2015).

Coming to the narratives of the informants of the research for this chapter, the owner of the spa explained that her customers "believe that if they drink the special milk for mamas, their baby will become more intelligent, and healthier" (Interview, 08/2015). Similarly, Veronique tells about her pregnant colleagues' practice of drinking milk. The women "really believe this is a kind of a rule - that a women needs to drink milk [no matter in what form] everyday" to aid the development of the unborn child (Interview, 08/2015). My, who worked in a hotel restaurant and was five months pregnant at the time of the research, had flavoured pregnant formula in the mornings and a glass of fresh milk in the evenings. Although she did not like the taste of the formula at all, she drank it regularly following the recommendations of her doctor and husband (Interview, 09/2015). 
The body ideal for pregnant women exhibits certain discrepancies. It is not uncommon that women gain between 20 and 25 kilogrammes during pregnancy (Fieldnotes, 09/2015). A woman the author met during pregnancy class, working in the TV business, had put on respective weight. She had to stop working in front of the camera early during her pregnancy, as her body was perceived as too big to be presented publicly. However, she followed her mother's and mother-in-law's advice to gain weight as this was supposed to be transferred to the developing foetus and ensure that she would have enough and solid breastmilk after delivery. Given that female adult bodies are socially valued for their slenderness (Leshkowich 2012), other women rejected pregnancy formula precisely because of its high calories and turned towards fresh milk instead (Fieldnotes, 09/2015). During pregnancy, on the one hand, the female body is pressured into weight gain by mothers and mothers-in-law. On the other hand, pregnant women try to comply with the slim female body ideal as well as with public health recommendations on reasonable weight gain (Mecuti n.d.). They aim for 'fat children and beautiful selves', for which the food and diet industry have 'tailor made' solutions, as was criticised by the social media user above.

In a context in which having children is deeply associated with being a 'proper' woman (Bélanger 2004), pregnancy constitutes a pivotal moment that make women work hard on their bodies for the sake of their unborn babies. The consumption of (flavoured) milk formula or liquid dairy products is regarded essential for the bodily connection between the pregnant woman and the unborn baby. The consumption of milk exhibits a strong dogmatic practice exemplifying technologies of the Self (Foucault 1988). Hence, its consumption even arouses negative visceral sensation and bodily indisposition within, some dislike the taste, and, yet, they selfdiscipline themselves to have it (Abbots 2017, 142). Through the example of milk in its various forms, it becomes visible how the family of the pregnant woman, the food industry, and the public health system all spotlight the pregnant body. For the mother-to-be, her own body turns into a contested space of social discourses and also becomes an object to herself that she regulates and moulds according to conflictive expectations. And these social expectations and pressures mothers-to-be sensually experience inside their bodies. When the breastmilk of the mother is disqualified for 
not being nurturing enough, feelings like shame and distress make themselves felt inside her body (Crossley 2012, 140). Embodying such discrepancies, women ingest the social expectations being placed on them as 'natural' caregivers. They are not only responsible for regulating the child's food-to which this chapter will turn to next-but also their own diets, appetites, and bodies.

\section{Body Ideals in Children: 'When the Dog Is Too Skinny, the Owner Should Feel Ashamed'}

"When the dog is too skinny ..." 15 — this Vietnamese saying was used by the social media user introduced above. It summarises the rationale behind the feeding of babies and young children in contemporary urban Vietnam (Vietnam's Nutrition Association 2017a). As will be shown, it captures an essential female concern: a child's skinny body physically exposes the maternal incapacity of caring for the ones most dependent.

Against the background of the country's war-torn past and the experience of famine and food scarcity deeply engraved into collective memory, the 'skinny dog' might also stand for former times dominated by a general lack of means for appropriate foodwork. Whereas the chubby child depicted in colonial advertisements (see above) aimed to impart the idea of colonial and urban exceptionalism (Peters 2012b, 46ff.), the increasing weight ratio of children today represents the general economic betterment and a more decent and luxurious urban life.

Loan explains that "[a] mother in HCMC likes her children fat" (Interview, 08/2015). Ly elaborates further on the association between body weight and health of the child:

The standard of a healthy child in our country is that of the fat child. When two mothers come together, they just care about how many kgs the child has. They don't care whether they [the children] are healthy or sick. Just how much food [the child eats] or how tall it is. (Interview, editor, 09/2015)

The societal importance assigned to well-nurtured children becomes apparent in this common greeting ritual. In many discussions with mothers and pregnant women it was repeated that when two mothers meet 
with their kids the first question is "how many kgs [kilogrammes does your child weigh]?” (Interview, representative research market institute, 09/2015; Fieldnotes, 08/2014).

As mentioned in an interview with Thi, herself a mother of a two-yearold daughter, she explained that when a child or baby is perceived as "underweight, people like your neighbours or your parents in law think that you are not a good mum" (Interview, 09/2015). She stresses that what falls into the 'normal' body range according to global biomedical body indices, qualifies as 'underweight' by the perception of her neighbours and in-laws. She articulates the pressure faced by mothers to regulate their children's bodies in ways to live up to the local norms of social status, health, and bodily beauty, which certainly do not coincide with the image of a 'skinny dog'.

Beauty in children becomes particularly manifest in bigger body sizes symbolising physical attractiveness, health, and socio-economic statusthe bigger, the higher the social prestige, and the 'skinnier' — as in the metaphor of the dog-the more to be looked down at the supposed lack of a mother's accountability towards her loved ones. In this process of social normalisation of the child's body, weight gain and the accumulation of fat become the top criteria not only for numerically measuring the development of the child but also for measuring the mother's quality of foodwork. The notion of 'a good mum' (một người mẹ tốt) constitutes a paramount marker inscribed onto the child's body. This is the way maternal care and affection supposedly materialise physically, as will the failure of maternal foodwork show in 'skinny dogs'. Being in sharp contrast to the official public obesity discourse fostering the healthy child, the presented weight-gain discourse normalises the child's chubby body shapebut into the opposite direction. It constitutes a competitive powerful discourse of truth carried on by family, in-laws, friends, and neighbours as bio-authorities.

\section{Feeding Practices: Between 'Raising Pigs' and Self- Determined Eating Subjects}

To achieve this body ideal in children requires certain ways of feeding the babies and toddlers. This obviously relates to the kind of food as well as 
to the quantities and the ways of being fed. A survey of 3000 parents $^{16}$ in urban areas conducted by the VNA in 2013 suggested that " $65 \%$ of parents did not feed their children properly” (Tuổi Trẻ Online 2013). Main reasons found were parents having too little time and grandparents taking on the role of caregiver, and the use of force and diversion when feeding children. In her outcry "[d] on't apply the mentality of raising ... pigs when raising your children" 17 the social media user set off an avalanche of online forum discussions about the proper way and common practices of feeding children in urban Vietnam. Her comparison deploys the analogy of raising children with industrially fattening pigs. The social media user recalls a typical morning at a food vendor shop when grandmothers, babysitters, and mothers come to have breakfast with their kids:

you will notice that someone will be bawling at, then soothing a crying baby and stuffing, forcing him/her to eat at all costs. The mothers would argue that 'if we leave it [eating] up to them, they will not at all be hungry all day long'. There are babies who are forced to eat on a daily basis five main and supplementary meals, then an extra six to seven times [feeding on] milk, to gain weight well and fast. (Vietnam's Nutrition Association 2017a)

She stresses the quantities eaten as well as the use of force applied to make the child eat. A common way of feeding children, substantiated in the data, can be called 'mobile feeding'. In many discussions women reported that grandmothers or babysitters would run with the spoon after the kids (Fieldnotes, 09/2014). Personal observations around the condominium bloc during the research stay matched such accounts of mobile feeding (Fieldnotes, 08/2015). By running after the kids with a bowl of congee and spoon, food is constantly being made available in order to guarantee the ingestion of 'enough' food. The use of TV and toys are other common means to distract the child's attention away from being stuffed while turning eating into a minor matter (Tuổi Trẻ Online 2013). On the issue of force, Thi explains further:

You can easily observe how mums feed their baby in Vietnam. Sometimes they force the babies to eat. So it is very different from other countries, especially in Europe. Because I heard lately, [there] they just feed the babies 
what they need. And just give them the food they can eat or they can say 'no'. But here we force them to eat ... and the kid or baby will be punished if they don't eat. (Interview, 09/2015)

The social media user shares her observation of mothers giving pills and medicines to their children to increase their appetites (Vietnam's Nutrition Association 2017a). Children vomiting because of overfeeding is nothing uncommon (Interview, Veronique, 08/2015). At the same time it is suggested to mothers that they discipline their child's eating behaviour by conditioning them to be hungry at certain times (Tuổi Trẻ Online 2014). Through the regulation of overindulgence, and vomiting as a consequence of being stuffed, the embodied feeling of satiety inside the body is naturally levelled out. The child's body as object is conditioned to eat and the subjective bodily and sensual experiences of taste and appetite externally retained while felt within.

The approach of feeding children 'properly' holds a strong generational dimension. While parents update with the modern parenting knowledge and practices, grandparents depend on their experiences to raise children (Tuối Trẻ Online 2013), thus oftentimes causing conflicts of the clashing ideas of how to feed and what the child actually needs. As elaborated earlier on, for the older generation which grew up in food-insecure times, the paramount expression of a female's ability to care for her child is the constant provision of food to nurture the child's body well and therewith to project the child's successful future (Peters 2012b, 48). According to Loan, mothers would feel overwhelmed by the sheer mass of information to which they have access nowadays. Information on feeding practices and food socialisation styles provided on the internet and social media becomes overwhelmingly abundant and calls the feeding practices of the older generation into question:

It is the old thinking when the child is fat, it is healthy. Now they change it, it changes. More people now they change thinking. For example, they share about the Japanese way to take care of the baby. Now we have a lot of information, from the internet. How to take care of your baby for health reasons, not fat. So now, for the modern mother it is difficult. More difficult to take care, because there are a lot of [conflictive] information. (Interview, 08/2015) 
Online research conducted for this study backs Loan's perspective on women struggling with overwhelming loads of diverse and oftentimes conflicting information as channels of food and nutrition knowledge have generally multiplied, as obviously have the recommendations for children's dieting methods. New truth discourses regarding the feeding of children proliferate and contradict the dominant weight-gain discourse. The desk study for this chapter revealed that nutrition counselling seems to be a professional and lay sector on the upswing. Medical intuitions such as hospitals and institutions under the Ministry of Health still dominate the scene (Interview, medical nutrition doctor, HCMC, 08/2017). However, online press and popular periodicals featuring food and nutrition columns have led to an explosive increase in the amount of accessible information. Blogs run by amateurs, such as 'experienced' mothers and so-called lifestyle influencers, social media forums, home-made online tutorials, and 'expert corners' on the websites of food companies make up the widening landscape of nutrition counselling which women, like Loan, consume for advice. The online research brought to light new trends of feeding babies and toddlers that divert from the 'mobile feeding' of blended congee as was described earlier on. Although the latter is still very popular, the so-called Japanesestyle and the baby-led weaning methods are strongly gaining in popularity (Vietnam's Nutrition Association 2017b). Following the Japanese style (phuóng pháp ăn dặm kiểu nhật), food is cooked and offered in its solid form when the child is three to five months old and breastfed in parallel. ${ }^{18}$ The method of baby-led weaning (phuóng pháp ăn dặm bé chi huy) offers solid food and puts the baby or toddler in charge of choosing what to eat from the plate and how to eat it-supposed to stress the discovery of the meal according to the child's own demand. ${ }^{19}$ According to the newspaper Tuổi Trẻ, children nutrition training programmes had started to include this method due to the high rates of 'anorexic' (biếng ăn) and picky eaters (kén ăn) in children from six months to five years old (Tuổi Trẻ Online 2017).

The internet is full of debates introducing, promoting, and condemning such emerging trends. The use of force when feeding babies and toddlers is increasingly called into question (Tuổi Trẻ Online 2013; VietNamNet 2015) as a way of passively 'stuffing' children. In the debate, 
'choice' comes in assigning to the child the ability to choose 'naturally' what feels best for it. The study of the Vietnam Nutrition Association argued that it would be common for parents to keep on feeding their children when they are over two years old and that this method would inevitably lead to a lack of independence in children and a feeling of being forced to eat at others' will (Tuổi Trẻ Online 2013).

In sum, on the one hand, women are captives of the two metaphors comparing children with 'skinny dogs' and 'fattening pigs' strongly guiding maternal foodwork. On the other hand, mothers are confronted with clashing feeding models given the diffusion of new 'options' via the internet. Besides the mothers' 'duty' to stuff their children they are increasingly called on to socialise their children into making selfinformed food choices. This latter feeding model of the child as eating subject focuses the child's attention towards its subjective embodied feelings of appetite and hunger and the bodily experience of taste. The different approaches locate women's foodwork between the extremes of forcing objects to eat and to let subjects chose. The latter resembles what is discussed as the quality of being a good mother in neoliberal parlance in the Global North, namely, in which mothers are held responsible for turning their children into self-experiencing subjects prepared for neoliberal ideals of choice and individual responsibility (Cairns et al. 2013). In this ambivalent context, mothers' biopower which resonates from nurturing their children becomes more complex and conflictive as does the fear of failure being regarded a 'good mother'. What is more, the qualities that make up a 'good mother' in the first place are negotiated and challenged through emerging competitive feeding practices.

\section{Normalisation of Bodies Growing(-up)}

Looking at a fat adult [in Vietnam], people will often criticise that the person is lazy, slow and doesn't exercise, or that he/she eats a lot or judge them in a more comforting way such as 'kind-hearted, gentle looking'. On the contrary, children are increasingly stuffed to be fat or even overweight. (Vietnam's Nutrition Association 2017a). 
In her quote, the same social media user relates to the social construction of what counts as normal and abject bodies being different for children and for (female) adults. The dominant weight-discourse materialising in chubby children's bodies invites the question of when the cuteness of growing bodies reaches a threshold that turns the chubby body into an abject fat teenaged or adult body. The process of normalisation of bodies as mentioned here refers to the categorisation of what is perceived as beautiful in body shapes, backed up by truth discourses that apply differently to a body's lifespan from childhood to adulthood.

In this regard, Loan considers the upbringing of her two daughters who are now teenagers. When they were children, they were taken care of by her mother-in-law while Loan was working. Because she was the first baby in the family, other people and her mother-in-law cared a lot about her oldest daughter by feeding her "a lot of everything, a lot of sweet and a lot of delicious foods". Nowadays, the first daughter has, according to Loan, to fight being overweight. Loan designed a workout programme for her to lose weight but she senses that her daughter "is not happy [at all], [as] she feels taught and controlled [by the workout programme]". But since they talked about the need to lose weight, her daughter would accept it. One of the arguments for losing weight mentioned by Loan to her daughter was that her daughter would feel "shy" about her body when having a first boyfriend. A similar reference to the overweight female body regarding amiableness, love, and potential for sexual relationships was brought up in an online video produced by a local TV production company, which focuses on urban lifestyle issues. Teenagers were interviewed on the topic of overweight. In small question and answer statements they shared perspectives and personal experiences with being addressed as 'overweight' in society. When asked whether her family would complain about her weight, one of the female interviewees shared with the audience: "my mom said no one would ever marry me, cause he wouldn't possibly be able to afford enough food for me" (Vi Sao Mâp? [Why are you fat?] 2017). Loan describes her second daughter as an absolute contrast. Put under the same feeding regime of the older generation, she nowadays "hates food. Hates [!]. This is the reason she now is very thin" (Interview, 08/2015). 
On the one hand, mothers are supposed to feed their kids and let go control of foodwork when giving the children to the grandmother to pursue wage labour. Concurrently, later on they are responsible for curbing the 'unhealthy appetites' of their adolescent children. As indicated in the opening quote by the social media user, the slim body ideal expects body control and containment from women (Ngo Thi Ngan Binh 2004) which is dissonant with the ideal of overweight children symbolising cuteness. Growing children partly reject the feeding regime applied on them as is seen, for example, in teenagers starting to hate or refuse food. Others go on diets and work out as they start feeling shy about their bodies, which seem no longer to correspond to the beauty ideal of slimness of their age. In a way, they become bio-authorities over their own bodies-but remain framed by conflicting socio-cultural images of ideal bodies. At the same time, mothers like Loan feel responsible for working on their child's body, for example, through preparing workout programmes for them. They direct their bio-authority over their children in the perceived need to prepare them for the next stage of adolescent body norms. An interview with a personal fitness coach depicted the growing demand of mothers registering their teenaged kids for rigorous body workout programmes with the main goal to slim them down (Interview, fitness coach, HCMC, 08/2017). In an interview with the Nutrition Centre in Hanoi it was indicated that anorexia nervosa is developing into an issue amongst teenagers feeling overweight and trying to avoid eating "to be in a good shape" (Interview, 09/2016). Oftentimes and beyond Vietnam, female teenagers find themselves struggling with the passage from childhood to adolescence, a struggle of the Self, in which the body becomes a central reference point (Bordo 1993). The rapid development from food scarcity to food abundance in the country poses intriguing questions regarding the connections between food consumption and body regulation, eating disorders, and body alienation. Whereas eating disorders such as anorexia nervosa are not covered by the truth discourse of the medical sciences or taken up by popular media in Vietnam yet, ${ }^{20}$ this does not say much about the social realities and experiences of lived bodies and their pursuit of embodying and rejecting discursive 'normalisation'. How this is elaborated in urban Vietnam constitutes an issue for further research. 


\section{Conclusion: Ambivalent Maternal Foodwork}

What runs like a thread through the narratives of the interviewees is the generational conflict between the mother and her own mother or motherin-law. Under the auspices of the older female generation in the household they feel urged to 'feed up' their infants as a "mum in Vietnam is influenced quite strongly by family, and from parents" (Interview, Thi, 09/2015). Ly describes doing things differently in terms of children's nutrition as an ambiguous endeavour. In the end, because of their insecurities, women would oftentimes comply with the common standards of feeding, because: "when I tried to do something different, I just felt like me against the world" (Interview, 09/2015).

Besides complying with the expectation to fatten up their children, they are confronted with contrary discourses that shift the eating child from the position of the passive body to an eating subject with intrinsic preferences and the freedom to choose. What is more, mothers increasingly do not only need to provide 'enough' and in a proper way for their children, but food should also qualify as safe since the navigation of food safety risks increasingly plays a role in responsible 'mothering' (see Faltmann, this volume; see Kurfürst, this volume).

The interview narratives showed the mundane ways that individuals used to govern themselves in everyday practices of eating and feeding (Foucault 1994). A tendency of technologies of responsibilisation crystallised, but not only in the sense of neoliberal governance and in its pursuit of health and well-being (Cairns and Johnston 2015, 33) but, contradictorily, for fatness and weight gain at the same time. It is in this context of conflicting and dynamic truth discourses regarding ideal body standards, norms of health, and feeding that mothers and mothers-to-be manoeuvre in. The child's body constitutes a contemporary contested object over which norms of health and beauty, food regulation, and responsibility are fought. Aligned with this dynamic is the negotiation of socio-cultural discourses on what constitutes 'a good mother'. Thus, both, the mother and the child embody these ambivalences and ambiguities through their lived experiences. The embeddedness of routinised and reflective female feeding practices at different scales revealed biopower as oscillating between different authorities and truth regimes. These are malleable and 
contested and in this way create a diffuse sense of anxiety on the side of mothers regarding their responsibility of feeding their children.

Through daily foodwork routines and the approach of food femininities, this chapter uncovered links between individual food and body performances at interpersonal and emotional levels and showed its embeddedness in wider social structures. Food as material matter crossed the bodily boundaries of the mother and the child. Feeding practices spoke to the "symbolic boundary of what it means to be seen as a 'good mother" as well (Cairns and Johnston 2015, 70). As was seen, the constant comparison with other mothers aimed for inclusion and exclusion in the boundary of 'good mother'. At the same time, the sympathy of many mothers expressed towards the social media user's critique of the diverse forms of pressure faced by women, adumbrates the alternative views on food femininities and the spaces for resistance against dominant truth discourses.

Overall it became clear that obesity is more than just a management problem to be tackled by a global set of intervention measures. This chapter aimed to uncover the local social complexities, interests, and conflicts beyond the medical categorisation of 'abject' and 'normal' bodies.

Acknowledgements This research was made possible through the generous support of the research project 'A body-political Approach to the Study of Food Vietnam and the Global Transformations' (P 27438) by the Austrian Science Fund (FWF). I deeply thank my colleagues in the project, Nora Katharina Faltmann and Carina Maier, for the engaged and inspiring feedback loops on various chapter drafts. Also thanks to Nir Avieli for his valuable input to this work. Furthermore, I want to express my gratitude to Thi Linh Hoang, who so reliably supported the online desk study for this chapter and for being an important gate-keeper to the field.

\section{Notes}

1. Vietnamese title 'Báo động trẻ béo bung', Tuổi Trẻ Online 2015.

2. For in-depth discussions on body discourses and practices in Asia, see Zheng and Turner 2009.

3. This chapter focuses on feeding as one aspect of foodwork, entailing cooking, shopping, planning for mealtimes, and so on, and understands it as labour and emotional and mental engagement (DeVault 1991). 
4. When using the term 'woman' in the following, it is used as understood by the dominant local discourse on femininity drawing strongly on biological dispositions. This is not necessarily the author's own understanding but drawn on to make sense of the local context rather than reflecting on the author's personal view.

5. For an in-depth discussion of middle classes in Vietnam, see Van Nguyen-Marshall et al. (2012); Welch Drummond (2012); Earl (2014); Ehlert (2016).

6. All following names are changed for reasons of anonymisation.

7. Most interviews were conducted in English. If otherwise, a Vietnamese interpreter supported the interview.

8. Thanks to Nora Katharina Faltmann, who conducted the interview as team member of the same research project 'A Body-Political Approach to the Study of Food - Vietnam and the Global Transformations'.

9. Quotes from newspaper paper articles and online documents in Vietnamese were translated into English.

10. In general, in Confucianist thinking society is glued together through moral obligations of control and deference between the ruler and the subjects, between parents and children, between husband and wife (Drummond and Rydstrøm 2004, 6ff.).

11. The Confucian concept of the four virtues ( $t \hat{u} d \hat{u} c$ ) defines the moral obligations for women to correctly behave bodily and verbally towards men and the elderly in society. The first virtue (công) refers to her domestic skills, the industriousness, and the selflessness of the woman. The second virtue (dung) defines the proper, modest outward appearance for woman. The third virtue (ngôn) demands female self-control in speech and emotions. Finally, the fourth virtue ( $h a n h)$ constitutes the ultimate outcome of a long process of self-control, self-sacrifice, and self-cultivation of a 'virtuous' woman (Ngo Thi Ngan Binh 2004).

12. See, for example, Crossley (2004) on why the common distinction in social theory of the body between the 'inscribed' (e.g. Foucault 1977) and the 'lived' body (e.g. Merleau-Ponty 1962) cannot be maintained.

13. The social media user posted her discussion in Vietnamese, which was translated into English (see also next endnote).

14. Her blogpost was word by word reprinted with her permission on the website of the Vietnam's Nutrition Association. Many other social media users, also young mothers, have reposted her social media thread supporting her critical views on mothers being scolded by society for their feeding practices (e.g. of having too fluid mother's milk or babies which are not considered chubby enough). 
15. The English translation from Vietnamese of "Chó gà̀y hổ mặt người nuồi".

16. By focusing on parents and the household level, gendered food allocation and responsibilities and gender inequalities within the household do not seem to have been appropriately considered in the large-scale survey (Charles and Kerr 1988; DeVault 1991).

17. The English translation from Vietnamese of "Nuôi con, dừng up dụng tu duy nuôi ... lợn".

18. The quantitative content analysis with an online search engine noted first entries on this feeding method in Vietnam in 2012, and ever since it is widely discussed online in terms of its pros and cons (e.g. Marry Baby 2017).

19. The term baby-led weaning started to appear online in Vietnam in 2015.

20. The online research using keywords like 'anorexia' (biếng ăn) did not yield significant matches. The author is aware that such a quantified approach can only be a first and very superficial step calling for the development of a qualitative research design to approach this sensitive topic in future research.

\section{References}

Abbots, E.-J., 2017. The Agency of Eating: Mediation, Food and the Body. Contemporary Food Studies: Economy, Culture and Politics. London; New York: Bloomsbury Academic.

Bélanger, D., 2004. Single and Childless Women of Vietnam: Contesting and Negotiating. Female Identity? In: Drummond, L., Rydstrøm, H. (eds). Gender in Contemporary Vietnam. Singapore: Singapore University Press, 96-116. Beresford, M., 2001. Vietnam: The transition from central planning. In: Rodan, G., Hewison, K. and Robison, R. (eds.). The political economy of Southeast Asia: conflict, crises and change. Melbourne: Oxford University Press, 206-233. Beresford, M., 2008. Doi Moi in review: The challenges of building market socialism in Vietnam. Journal of Contemporary Asia 38(2), 221-243.

Bordo, S. 1993. Unbearable Weight: Feminism, Western Culture, and the Body. Berkeley: University of California Press.

Cadilhon, J.-J., Moustier, P., Poole, N. D., Phan Thi Giac Tam, Fearne, A. P., 2006. Traditional vs Modern Food Systems? Insights from Vegetable Supply Chains to Ho Chi Minh City (Vietnam). Development Policy Review, 24(1), 31-49. 
Cairns, K., Johnston, J., MacKendrick, N., 2013. Feeding the 'organic child': Mothering through ethical consumption. Journal of Consumer Culture 13, 97-118.

Cairns, K., Johnston J., 2015. Food and Femininity. London; New York: Bloomsbury Publishing (Contemporary Food Studies: Economy, Culture and Politics).

Carolan, M. S. 2011. Embodied Food Politics. Farnham; Burlington: Ashgate (Critical Food Studies).

Charles, N., Kerr, M., 1988. Women, Food and Families. Manchester and New York: Manchester University Press.

Clapp, J., Scrinis, G., 2017. Big Food, Nutritionism, and Corporate Power, Globalizations, 14:4, 578-595.

Collins, P.H., 1994. Shifting the Center: Race, Class and Feminist Theorizing about Motherhood. In: Bassin, D., Honey, M., Kaplan, M. (eds.). Representations of Motherhood. New Haven, CT: Yale University Press, 56-74.

Counihan, C., 1999. The Anthropology of Food and Body. London: Routledge. Crossley, N. 2004. Body-subject/body-power: agency, inspiration and control in Foucault and Merleau-Ponty. In: The Aberdeen Body Group (ed.). The Body. Critical Concepts in Sociology, 219-235.

Crossley, N., 2012. Phenomenology and the Body. In: Turner, B.S. (ed.). Routledge Handbook of Body Studies. New York: Routledge, 130-143.

Csordas, T.J., 1994. Introduction: The body as representation and being in the world. In: Csordas, T.J. (ed.). Embodiment and Experience: The Existential Ground of Culture and Self. Cambridge: Cambridge University Press, 1-26.

DeVault, M. L. 1991. Feeding the Family: The Social Organization of Caring as Gendered Work. Chicago: University of Chicago Press (Women in Culture and Society).

Drummond, L., Rydstrøm, H. (eds.), 2004. Gender Practices in Contemporary Vietnam. Singapore: Singapore University Press.

Earl, C. 2014. Vietnam's New Middle Classes: Gender, Career, City, Gendering Asia. Copenhagen: NIAS.

Ehlert, J., 2016. Emerging consumerism and eating out in Ho Chi Minh City, Vietnam. The social embeddedness of food sharing. In: Sahakian, M., Saloma, C.A., Erkman, S. (eds.). Food Consumption in the City: Practices and patterns in urban Asia and the Pacific, Routledge studies in food, society and the environment. London; New York: Routledge, 71-89.

Foucault, M., 1977. Discipline and Punish: The birth of the prison. New York: Random House. 
Foucault, M., 1988. Technologies of the Self. In: Martin, L. H., Gutman, H., and Hutton, P. H. (eds.). Technologies of the Self: A Seminar with Michel Foucault. London: Tavistock, 16-49.

Foucault, M., 1994. The Political Technology of Individuals. In: Faubion, J. (ed.). Michel Foucault: Power. New York: The New Press.

Greenhalgh, S., 2016. Neoliberal science, Chinese style: Making and managing the 'obesity epidemic'. Social Studies of Science 46(4), 485-510.

Guthman, J., 2009. Teaching the Politics of Obesity: Insights into Neoliberal Embodiment and Contemporary Biopolitics. Antipode 41(5), 1110-1133.

Hai Thi Hong Nguyen, Wood, S., Wrigley, N. 2013. The emerging food retail structure of Vietnam. Phases of expansion in a post-socialist environment. International Journal of Retail \& Distribution Management 41(8), 596-626.

Harvey, D., 2005. A Brief History of Neoliberalism. New York: Oxford University Press.

Jing, J., (ed.), 2000. Feeding China's Little Emperors. Stanford: Stanford University Press.

LeBesco, K., 2011. Neoliberalism, Public Health and the Regulated Body. London: Sage.

Leshkowich, A.M., 2012. Finances, Family, Fashion, Fitness, and ... Freedom? The Changing Lives of Urban Middle-Class Vietnamese Women. In: Van Nguyen-Marshall, Drummond, L. B. W., Bélanger, D. (eds.), 2012. The Reinvention of distinction: modernity and the middle class in urban Vietnam. Dordrecht: Springer (ARI -Springer Asia Series), 95-114.

Lupton, D., 1997. The Imperative of Health and the Regulated Body. London: Sage.

Lupton, D., 2013. Fat. Abingdon; New York: Routledge.

Marry Baby. 2017. Tập cho bé ăn dặm kiểu Nhật nhu thế nào? (How to train your baby to eat solid food using the Japanese method?). [online] Available at: http:// www.marrybaby.vn/nuoi-day-con/an-dam-kieu-nhat-thuc-don-va-phuongphap-an-dam [Accessed 30 March, 2018].

Mecuti: Kiến thức nuôi con - làm đẹp cho phụ nữ Việt. (n.d.). Mẹ bà̀u tăng bao nhiêu cân là chuẩn - Múc tăng cân trong thời kỳ mang thai các mẹ bà̀u nên biêt (How much weight should a pregnant woman gain? Recommended weight gains during different stages of pregnancy which mother-to-be's should know). [online] Available at: https://mecuti.vn/me-bau-tang-bao-nhieu-can-la-chuan-muc-tangcan-trong-thoi-ky-mang-thai-cac-me-bau-nen-biet.html [Accessed 3 Apr. 2018]. Mergenthaler, M., 2008. The Food System Transformation in Vietnam: Challenges for the Horticultural Sector Posed by Exports and By Changing Consumer Preferences. Dissertation, Universität Hohenheim. 
Merleau-Ponty, M., 1962. The Phenomenology of Perception. London: Routledge.

Metzl, J.M., Kirkland A. (eds.), 2010. Against Health: How Health Became the New Morality. New York: New York University Press.

Monaghan, L.F., Hollands, R., Pritchard, G., 2010. Obesity Epidemic Entrepreneurs: Types. Practices and Interests. Body and Society, 16(2), 37-71. Nestlé, M., 2013. Food politics. How the Food Industry Influences Nutrition and Health, Revised and Expanded Tenth Anniversary Edition. University of California Press.

Ngo Thi Ngan Binh, 2004. The Confucian Four Feminine Virtues (tu duc): The Old Versus the New - Ke thua Versus Phat huy. In: Drummond, L., Rydstrøm, H. (eds.). Gender Practices in Contemporary Vietnam. Singapore: Singapore University Press, 47-73.

Nguyen Cong Khan, Ha Huy Khoi, 2008. Double burden of malnutrition: the Vietnamese perspective. Asia Pacific Journal of Clinical Nutrition 17(S1), $116-118$.

Parsons, J. M., 2015. Gender, class and food: families, bodies and health. London; New York: Palgrave Macmillan (Palgrave Macmillan Studies in Family and Intimate Life).

Peters, E.J., 2012a. Appetites and Aspiration in Vietnam: Food and Drink in the Long Nineteenth Century. Plymouth: AltaMira Press.

Peters, E.J., 2012b. Cuisine and Social Status Among Urban Vietnamese, 188-1926. In: Van Nguyen-Marshall, Drummond, L. B. W., Bélanger, D. (eds.), 2012. The Reinvention of distinction: modernity and the middle class in urban Vietnam. Dordrecht: Springer (ARI -Springer Asia Series), 43-58.

Q \& Me Vietnam Market Research, (2016). Asia Plus Inc. [online] Available at: https://qandme.net/en/report/Fast-food-eating-behavior-and-popularchains.html [Accessed 03 April, 2018].

Rabinow, P., Rose, N., 2006. Biopower today. BioSocieties, 1, 195-217.

Rydstrøm, H., 2004. Female and Male "Characters": Images of Identification and Self Identification for Rural Vietnamese Children and Adolescents. In: Drummond, L., Rydstrøm, H. (eds). Gender in Contemporary Vietnam. Singapore: Singapore University Press, 74-95.

Rydstrøm, H., 2011. Comprised Ideals: Family Life and the Recognition of Women in Vietnam. In: Rydstrøm, H. 2011: Gendered Inequalities in Asia. Configuring, Contesting and Recognizing Women and Men. Copenhagen: NIAS Press.

Shilling, C., 2002. Culture, the "sick role" and the consumption of health. British Journal of Sociology, 53(4), 621-638. 
Shilling, C., 2012. The Body \& Social Theory. 3rd ed. London: Sage.

Sobal, J., 1999. Food System Globalization, Eating Transformations, and Nutrition Transition. In: Grew, R. (ed.). Food in Global History. Boulder: Westview Press, 171-193.

Socialist Republic of Vietnam, 2012. National Nutrition Strategy for 2011-2020, with a Vision toward 2030. Hanoi: Medical Publishing House.

Tuổi Trẻ Online. (2013). 65\% cha mẹ cho con ăn không đúng cách, vì sao? (65\% of parents did not feed their children properly, why?). [online] Available at: https://tuoitre.vn/65-cha-me-cho-con-an-khong-dung-cach-vi-sao-544280. htm [Accessed 30 Mar. 2018].

Tuổi Trẻ Online. 2014. Con ăn giặm, mẹ chớ vội (Mums should not hurry while feeding babies solid food). [online] Available at: https://tuoitre. vn/\%E2\%80\%8Bcon-an-giam-me-cho-voi-640483.htm [Accessed 30 Mar. 2018].

Tuổi Trẻ Online. 2015. Báo động trẻ béo bụng (Alert: children with fat bellies). [online] Available at: https://thethao.tuoitre.vn/tin/comment/964332.html [Accessed 30 March, 2018].

Tuổi Trẻ Online. 2017. Cho trẻ ăn dặm Theo phương pháp bé chỉ huy (Applying the baby-led weaning method to feeding babies sold food). [online] Available at: https://tuoitre.vn/cho-tre-an-dam-theo-phuong-phap-be-chihuy-1309392.htm [Accessed 30 Mar. 2018].

Van Nguyen-Marshall, Drummond, L. B. W., Bélanger, D. (eds.), 2012. The Reinvention of distinction: modernity and the middle class in urban Vietnam. Dordrecht: Springer (ARI -Springer Asia Series).

Vietnam Ministry of Health. 2012. General Nutrition Survey 2009-2010. Hanoi: Medical Publishing House.

Vietnam, Ministry of Health. 2016. National Survey on the Risk Factors of Non-Communicable Diseases (STEPS) Vietnam 2015. Hanoi: General Department of Preventive Medicine.

VietNamNet. 2015. 10 lời khuyên dinh dưỡng mọi bà mẹ cần biết (10 pieces of advice on nutrition and feeding practices which mums should know). [online] Available at: http://vietnamnet.vn/vn/doi-song/10-loi-khuyendinh-duong-moi-ba-me-can-biet-273023.html [Accessed 30 Mar. 2018].

Vietnam's Nutrition Association (Hội Dinh Dưỡng Việt Nam). (2017a). Nuôi con, đừng áp dụng tư duy nuôi lợn (Don’t apply the mentality of raising pigs when raising your children). [online] Available at: http://hoidinhduong.vn/ be-yeu/nuoi-con-dung-ap-dung-tu-duy-nuoi-lon-905.html [Accessed 30 Mar. 2018]. 
Vietnam's Nutrition Association (Hội Dinh Dưỡng Việt Nam). 2017b. Phương pháp ăn dặm khoa học (The scientific method of feeding). [online] Available at: http://hoidinhduong.vn/be-yeu/phuong-phap-an-dam-khoa-hoc-862. html [Accessed 03 April, 2018].

Waibel, G., Glück, S., 2013. More than 13 million: mass mobilisation and gender politics in the Vietnam Women's Union. Gender \& Development 21(2), 343-361.

Walls, H. P., Peeters, A., Pham, Thai Son, Nguyen, Ngoc Quang, Nguyen, Thi Thu Hoai, Do, Dan Loi, Nguyen, Lan Viet, Pham, Gia Khai, Reid, C. M., 2009. Prevalence of underweight, overweight and obesity in urban Hanoi, Vietnam, Asia Pacific Journal of Clinical Nutrition, 18(2), 234-239.

Welch Drummond, L. B., 2012. Middle Class Landscapes in a Transforming City: Hanoi in the 21st Century. In: Van Nguyen-Marshall, Drummond, L. B. W., Bélanger, D. (eds.), 2012. The Reinvention of distinction: modernity and the middle class in urban Vietnam. Dordrecht: Springer (ARI Springer Asia Series), 79-94.

Werner, Jayne, 2009. Gender, Household and State in Post-Revolutionary Vietnam. Oxon, New York: Routledge.

WHO - World Health Organization, 2000. Obesity: Preventing and Managing the Global Epidemic. Report of a WHO Consultation. Geneva: WHO.

WHO - World Health Organization, 2018. Obesity and overweight. Fact sheet.

[online] Available at: http://www.who.int/mediacentre/factsheets/fs311/en/ [Accessed 03 January, 2018].

Wright, J., Harwood, V. (eds.), 2009. Biopolitics and the 'Obesity Epidemic': Governing Bodies. New York: Routledge.

Zheng, Y., Turner, B.S., 2009. The Body in Asia. New York: Berghahn Books.

\section{Video}

Vì Sao Mập? [Why are you fat?]. (2017). [video] Directed by BomTV. Vietnam: BomTV. Available at: https://www.youtube.com/watch?v=ofvVarfHNJw [Accessed 30 Mar. 2018]. 
Open Access This chapter is licensed under the terms of the Creative Commons Attribution 4.0 International License (http://creativecommons.org/licenses/ by/4.0/), which permits use, sharing, adaptation, distribution and reproduction in any medium or format, as long as you give appropriate credit to the original author(s) and the source, provide a link to the Creative Commons licence and indicate if changes were made.

The images or other third party material in this chapter are included in the chapter's Creative Commons licence, unless indicated otherwise in a credit line to the material. If material is not included in the chapter's Creative Commons licence and your intended use is not permitted by statutory regulation or exceeds the permitted use, you will need to obtain permission directly from the copyright holder.

(c) 